\title{
ARTICLE \\ Building Pattern Technique of an Indigenous Community - Does Its Appearances a Distinctive Representation?
}

\author{
Md. Mustafizur Rahman ${ }^{1 *}$ Mohammad Tanvir Hasan ${ }^{1}$ Shahidul Islam $^{1}$ Jiaul Hassan Mithun ${ }^{2}$ \\ 1. Department of Architecture, Shahjalal University of Science \& Technology, Sylhet, Bangladesh \\ 2. Shahjalal University of Science \& Technology, Sylhet, Bangladesh
}

\section{ARTICLE INFO}

Article history

Received: 21 June 2021

Accepted: 10 August 2021

Published Online: 20 August 2021

Keywords:

Rakhaine

House pattern

Settlement pattern

Distinctiveness
Indigenous

\begin{abstract}
Bangladesh is enriched with beautiful traditional indigenous cultures. Different indigenous peoples with their distinctive existences also considerably create an enhance values and lifestyles to the socio-cultural sectors of Bangladesh ${ }^{[1]}$. Habitually, these indigenous communities have been comparable to live a large combined family to shear their lifestyles ${ }^{[2]}$. Presently the country has 45 indigenous communities who are living in different locations. All indigenous people within this country have their own style to build their settlements with special techniques to keep them safe and sound from all types of natural and environmental vulnerabilities and also enhance their knowledge of construction techniques and lifestyle. Rakhain is one of them with very small number of people are still living in different regions within the country which have their own system of building techniques. Study found that for several hundreds of years Rakhains are strictly following their indigenous prescription of house and settlement pattern. Although like other indigenous people of this country, they have mountains of problems, such as forced land occupation, lack of security and minority characteristics. Above all, forced political separation has gradually drowned them in the abysmal pit of marginal destiny. This has turned them into exiles in their own land. As a result, many of them are being forced to leave the country and as a result they misplaced their native knowledge and technique to construct. Thus, this study will initially focus on to search for the distinctiveness of their settlement pattern and building construction techniques and lifestyle. Again, in view of their problems, knowledge and experiences concerning archetype, built and house pattern, this study will finally explain how Rakhains accumulate their every distinctiveness from history and for present and future invention.
\end{abstract}

\section{Introduction}

According to Smith M., (2019), an estuarine territory of over 36,000 square kilometres, modern-day Rakhine State or Arakan State (Figure 1) stands on a strategic crossroads in Asia. Its borders mark three geo-political meeting-points: between Myanmar, Bangladesh and India; South and Southeast Asia; and the Buddhist and Muslim worlds ${ }^{[3]}$. Although there have been not enough accurate results about the total population presently living in $\mathrm{My}-$ anmar perhaps census shows the population of Rakhine may be $5.53 \%$ of Myanmar's total population. From the

*Corresponding Author:

Md. Mustafizur Rahman,

Department of Architecture, Shahjalal University of Science \& Technology, Sylhet, Bangladesh;

Email:mustafiz_su@yahoo.com 
$16^{\text {th }}$ century several Arakanese were living in the Chittagong Hill Tracts of Bangladesh who are known as Marma. They have been living in this area subsequently the Arakanese kingdom's control over the Chittagong region.

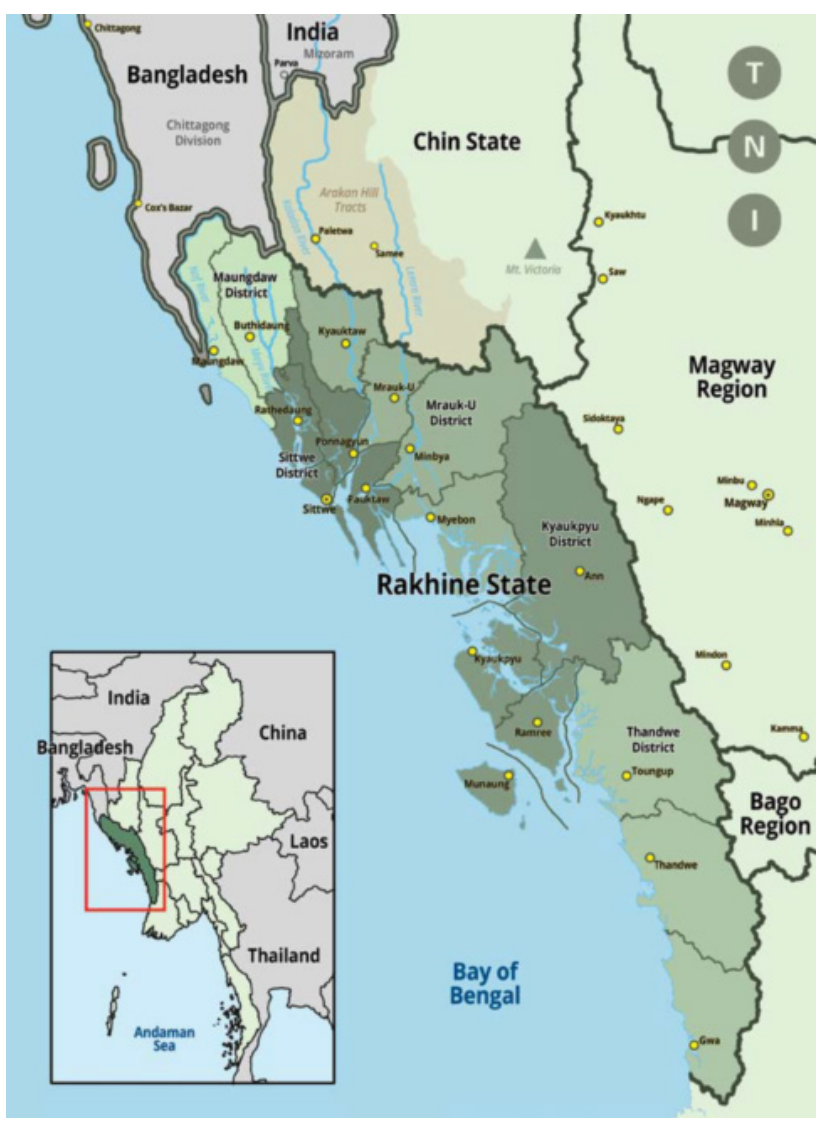

Figure 1. Present location of Rakhine or Arakan State; Source: Smith M., (2019)

However, in 2005, Majid Mustafa explained that in Bangladesh mostly Rakhaines are anthropologically of Mongoloid origin. Presently they have been living in Cox's Bazar, the coastal areas of greater Patuakhali and Bandarban area as well. In Cox's Bazar and Patuakhali area this Mongoloid tribe calls themselves Rakhaines. Once again, the same tribe calls themselves Marmas in Bandarban region. Originally this group of tribes historically came from neighboring Burma (Myanmar) and Manipur area (eastern state of India) ${ }^{[4]}$.

Now this tribe is living with the neighboring villagers near the sea area as permanent settlers. Although, there has been lots of arguments and opinions about the history of their families, living reasons in this area and period of their settlement. Meanwhile historians explain about the same background and the processes of their coming and their settling. Similarly, historians explain that their anthropological identity and life style are similar but in certain spheres-especially socio-economic and administra- tive-characteristics of dissimilarity are seen, even though they have the most beautiful, creatively and naturally built community houses with no use of artificial techniques. This study believes that these techniques may help them to enrich their culture and lifestyle and take these rich assets to furthermore which may introduce them to the world in contemporary approach. For various reasons currently Rakhaine tribe is on the edge of changing their culture and lifestyle. It is a transitional point to maintain their ethnicity and comparable to the contemporary techniques which can take shape in reality. For this reason, they might lose their own culture and lifestyle, their distinctive potential of culture and follow the path of self-realization. Therefore, the study realizes the fact that they are very special, the way they have merged themselves with nature and lived there for hundreds of years are the examples of sustainability in their very own way. The study also believes that their living, life style should be preserving for continuing to enrich their heritage which can further extent our culture and lifestyle.

However, indigenous community like Rakhaines in Bangladesh was largely built without formally trained professionals. Buildings were built by local construction workers, typically consisting of mistris (carpenters, roof builders), rajmistris (masons) and kamlas (helpers), together with household or community members. Despite not being the designed product of a professional, such buildings continued to accommodate and serve the needs of the great majority of the population. In that sense, and being such a significant part of the built environment, such buildings represented a fundamental form of distinctiveness that had evolved according to context-specific characteristics and resources. Therefore, this paper firstly tries to make out the cultural practice, building material and technique of this community which they practiced from hundreds of years. Once again, this paper creates an opportunity and scope for them to persist and preserve these distinctive techniques with all valuable documents.

\section{Background of Rakhines in Bangladesh}

History discovered that the word "Rakhine" was mainly originated from pali word "Rakkhapura" or "Rakkhaspuri". Later the name was changed to "Apovrongsho" and named Rakhine kingdom ${ }^{[4]}$. The name Rakhine was known to Arakan by English, Bengali and Portuguese people. The Rakhine race is blended with Aryan and Mongolian. Their heritage is also similar with Burmese (Cho, V., 2017) ${ }^{[5]}$. Many historians argued that Buddhism was introduced to Rakhine pray and Lord Buddha visited Rakhine pray in 554 B.C (Tun Shwe Khaing 1995) ${ }^{[6]}$. How- 
ever, the Rakhines are considered conservative in order to preserve their culture and custom but they have their own independent nation. In addition, Rakhine in Bangladesh have a rich custom and history that was originated since 3325 B.C. ${ }^{[7]}$. In 1975, Bangladesh District Gazetteers described that there was a close commercial relationship between Chittagong and Arakan and has a frequent communication between them. According to Oo, Saw Tun (2005), in 1784, the Burmese king Bodofoa took advantage of Rakhaine weakness and won over Rakhaine-Pray (Arakan) that resulted genocide where many people were killed ${ }^{[8]}$. Consequently, many Rakhaines escaped to the adjacent places controlled by the East India Company. The consequences lead to growing population of Rakhaines in Cox's Bazar, Chittagong, Bandarban, Rangamati, Khagrachari, Patuakhali and Barguna districts. In 2013, Islam Md Ashadul argued that "the first settlement in Bangladesh, in 1784 to be free from the oppression of Barmi king 150 families with 50 boats through the Bay of Bangal from an isolated area under the district of "Swanday" in Arakan's "Meghbarthi" came to Cox's Bazar" [9]. In 1964, Hall explained that Captain Hiram Cox was the first officer appointed to superintend the Rakhaine settlement at Cox's Bazar in July, $1799^{[10]}$.

However, in 2000, Ahmed Mohsin showed - "The national struggle of Rakhaine people from 1784 to 1824 was hardly progressing and, sandwiched between the two invaders, the Burmese feudalists controlled up to the eastern bank of the Naaf River and the British up to the western side of it. Both the aggressors had a common interest of keeping the Rakhaines land as their respective colonies. The Burmese controlled Rakhaine-Pray along with Assam, Manipur and Tanasserem were annexed to the British Empire after the 1st Anglo-Burmese War in 1825 and the remaining of part of upper Burma was also annexed in $1886^{\prime \prime 11]}$. Once again, Khaing T. S. (1994) explained that the history of Rakhine is depressing due to violence, treachery, forced distortion and repression by alien vested quarters and colonialists but even today they are facing an international conspiracy that with the help of shameful lies project their homeland as belonging to an alien race introduced by colonial forces ${ }^{[15]}$. According to Aung M. B. (2008), later than British rule over both side of Naaf River until $14^{\text {th }}$ august, 1947 , the people living on the western side saw a birth of a new nation called East Pakistan and the subjects there were labeled as East Pakistanis. On the other hand, the same stock of people living on the east of Naaf River saw a birth of another nation called Union of Burma and their subjects were Burmese- irrespective of race, religion and culture, language, etc ${ }^{[12]}$.

\subsection{Etymology}

In 2019 Martin Smith explained that due to its singular geography, Rakhaine,s peoples and politics were historically isolated from the kingdoms of the Bamar and Mon peoples who lived in the plains of the Ayeyarwady (Irrawaddy) and Sittoung river valleys to the south and east. Rather, protected by the forests and mountains of the ArakanYoma, most human habitation developed along a coastal strip of muddy creeks and winding rivers that run down to the Bay of Bengal ${ }^{[3]}$. However, conferring to Mohajan and Haradhan in 2018 - the name of Arakan is very ancient. This word Arakan came from Arabic or Persian origin, which has same meaning in both of these languages. Early Buddhist missionaries called Arakan "Rekkha Pura". In a Latin Geography (1597) by Peta Vino, the country was referred to as Aracan. Friar Manrique (16281643) mentions the country as Aracan (Ullah, 1997). The British travelers Relph Fitch (1586) referred to Arakan by the name of Rocon. Tripura Chronicle Rajmala mentions the name of Arakan as Roshang. The Muslims who have long settled at Arakan called the country 'Rovingaw' and called themselves 'Rohinga' or native of Arakan. The Chakmas and Saks of the 18th century called it 'Roang'. At present the Muslims of Arakan call the country 'Rohang' or 'Arakan' and call themselves 'Rohingya' or native of Rohang. The Burmans call themselves 'Rakhine' and call the country 'Rakhine Pye,' or country of Rakhine (Ullah, 1997) ${ }^{[13]}$. Following Table 1 shows the number of Rakhaine in three different countries.

Table 1. Number of Rakhaines in three different countries

\begin{tabular}{cc}
\hline Location & Number \\
\hline Burma / Myanmar & $3,107,000$ \\
Bangladesh & $2,07,000$ \\
India & 32,000 \\
\hline
\end{tabular}

Source : Smith, 2019

\section{Enthropologic Identity of Rakhine in Ban- gladesh}

\subsection{Geographical Perspective and Demographic Status}

Presently in Bangladesh Rakhine people settled down mostly in Cox's Bazaar, Bandarban, Patuakhli and khagrachari district. Following Figure 2 shows a distinctive rakhaine's settlement in patuakhali, Bangladesh. Geographically these areas are near to Arakan and Burma (Myanmar) from where the Rakhine had been migrated since many years. In addition, the natural landscape, materials and environmental 
conditions of these areas is also conducive for their settlements. According to Majid Mustafa in 2005, explained that this area is surrounded with several hills, rivers and upward slopes which are the important reason for migrating here. There are also green deep forests and bushes within this area which are again key factors for settling here. This reason is called the Anthropological Museum of the country since about ethnic minorities groups are living here ${ }^{[4]}$. Presently about 13 ethnic groups are living in this area where the number of Rakhine is about 1, 55,854. Following Table 2 shows the number of statistics of Marma-Rakhaine population in Bangladesh in different places and years.

Table 2. The statistics of Marma-Rakhaine population in Bangladesh

\begin{tabular}{ccc}
\hline Name of the Place & Year & Total Number \\
\hline \multirow{3}{*}{ Cox's Bazar Town } & 1799 & 10,000 \\
& 1872 & 3,205 \\
& 1982 & 1,012 \\
\hline \multirow{3}{*}{ Bandarban District } & 1901 & 16,608 \\
& 1981 & 79,518 \\
& 1991 & 59,228 \\
\hline \multirow{3}{*}{ Greater Patuakhali } & 1951 & 12,278 \\
& 1961 & 16,394 \\
& 1974 & 4,293 \\
& 1981 & 3,668 \\
& 1991 & 3250 \\
\hline
\end{tabular}

Source: (Majid Mustafa 2005)

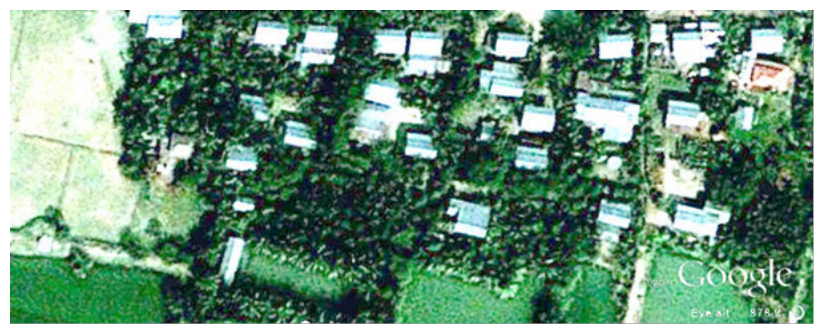

Figure 2. Top view of Rakhaine's settlement or Para (Satan Para, Patuakhali, Bangladesh)

Source: Goggle Earth

\subsection{Socio-economic and Cultural Perspectives}

For many years agriculture is the main economy of the Rakhine people in our country. They used to follow their own primitive process for cultivation since the beginning (Baird R., 2008) ${ }^{[14]}$. The cultivation systems of Rakhine and Bengalese are similar therefore the settlement pattern of Rakhine which basically dominated by the cultivation method are quite similar to Bengalese settlement. Except their agriculture economy they also have their individual techniques of weaving cloths by their own handloom. They produced salt for themselves and molasses as well. However, the Rakhine were surrounded by river but they never took fishing as their profession. They only tried to manage their economic needs by their own resources and agriculture production. In spite of confronting many natural disasters and famines, Rakihine people could overcome without any help and support from the past. But in the late fifties, some Muslim Bengalese within these areas has been tried to invade their land illegally which disrupted their economic conditions. Rakhine believes in Buddhism mostly. As they were self reliant with both landed property and wealth therefore, they never hesitate to build huge temple, cemeteries, and well paved pond in their community. Rakhine women were used to wear their own made dresses which were very elegant and ornamentation in style. To observe and perform the religious festival is one of the significant parts of their cultural heritage. They kept themselves busy to perform religious activity and festivals particularly concerning the full moon (Purnima), Buddha Purinam, Probarona Purnima, and Magi Purnima. They also spent money for various ceremonies including "Naior" (marriage related occasion). Most of their cultural performances are similar to Hindu Bengalese of Bangladesh (Majid Mustafa 2005) ${ }^{[4]}$.

\subsection{Settlement and Custom}

Rahaines generally lives in groups where the permission of group leader is mandatory for an individual in order to build new house within their territory. They prefer flat area as their neighborhood along the river. From the beginning they have been started to live in a small group with limited spaces. Now it is very common that within few years their family members have been increased and for this reason the settlement become very crowded. Even traditionally they don't have backyard and front space like Bengalese settlement. Due to this lack of space, the luxury to accommodate separate space for individual gardening (Basil plant) like Bengali Muslim and Hindu community is absent within their settlement. But every Rakhine village has its own temple, library and pond within the community. The space is considered as major community space or public space for the whole community. People gather in order to perform their daily household activity and religious performance. In these reasons the house pattern of Rakhine is different from Bengalese. Like other mongoloid races they also make high platform to build their houses. This kind of distinctive elevated house pattern and unique roofing system make it easy to identify Rakhine village for very distance. Currently for lack of local material availability the roof material of their houses has been altered to tin (corrugated sheet) from leaves of palm. Figure 3 shows geographical mapping of Rakhaine settlement in Patuakhali of Bangladesh. 


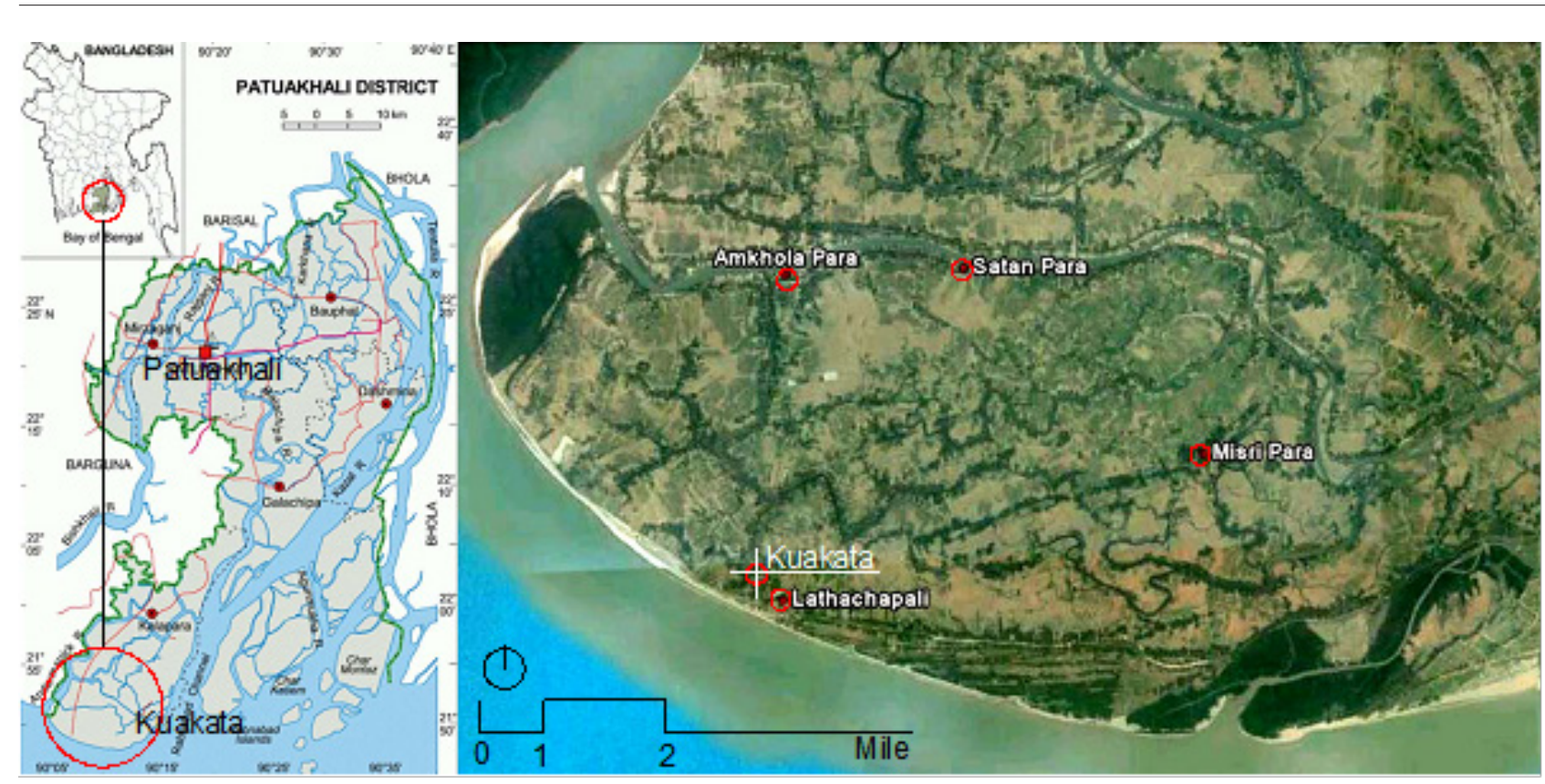

Figure 3. Geographical mapping of Rakhaine settlement in Patuakhali, Bangladesh

Source: Author 2017

\section{House and Settlement Type of Rakhaine in Bangladesh}

Currently the Rakhaines of Bangladesh are settling down the greater district of Patuakhali and Cox's Bazar. But few of them are living in Khagrachari. In this research the information was collected from different Rakhaine Para at Kuakata in the greater district of Patuakhali which is located in the extreme south of Bangladesh. Therefore, the settlements of some different Rakhaine Para at Kuakata (Amkhola Para, Lathachapali, Misri para, and Satan Para; Figure 2) in Patuakhali were selected and surveyed in this study (Figure 3).

\subsection{Housing and Custom}

Rakhaines have generally built their houses on the bank of the rivers or in the coastal plain lands. They live in groups and make their houses alongside, which together make an entity of society. This kind of entity is called para (Rakhaine village). Before building a house, everyone needs to get the permission of the leader or Mathobbar (head man) of the society. Typically, the area has been leased in the name of an ancestor. However, typically Rakhaine houses are made of local materials that are easy to get and available which represents the distinctive features of architecture and their traditional image.

In every village there is a Buddhist temple, library, big ponds, etc., which are open for all of the community. But there is prohibition of using the pond, because they think that the sanctity of the water becomes violated if one gets down into it. They consider water as the symbol of purity as it carries the essence of the power that washes away all the sins. This next Figure 4 and 05 shows the settlement pattern of a Rakhaine Para and individual house pattern of the study area.

\subsection{Settlement Pattern}

Rakhines prefer land for their settlement where the topography is comparatively flat. They also have a preference river site to rest the settlement in order easy harvesting system. The organization of the settlement is linear and elongated to east west direction which shown in Figure 2 and Figure 3. A linear corridor parallel to settlement connects all the houses. Each settlement consists of a Buddhist Bihara, a tree of God, a school, a reserved pond where people gather for communal and house hold activity during religious festival and an area for Headman where he took the major social decision for the community. Usually, all houses are located on the both side of the land and create a linear circulation spine.

\subsection{House Pattern}

Houses are built on stilt which locally called "tong". This system gives privacy, protects from wiled beast, cyclone, flood and also hygienic. Mainly, the Rakhine house is comprised of two layers and rectangular in shape. Lifted area is making use of main living space enclosed by the wooden curtain walls whereas the ground floor is more open made use of service area and other household 
activity (Figure 5). Stair leads to entrance platform attach two layers. Lower area is connected with main artery of the settlement which used as handloom area (Photograph 3 , Weaving area and family activity area), store, outdoor sitting and other services. The upper large platform holds private room, dining area, kitchen, toilet and prayer room. Prayer room remains separate from another zone but connected with main platform. The dining area, a semi open space is situated in the north side covered by pitched roof. Often, they intend to extent semi open space by using offset porches around the built form.

\subsection{Roofing}

The roofing system is distinctive and different from traditional Bengalese houses. Rakhines often use pitch or gable roof is used with different orientations for different activities (interior or exterior) which is made of tin (corrugated sheet) and leave of palm as well. This style frequently uses lower pitched gable roofs (Photograph 2) with front-facing gables. The roof system is more ornamented often emerge in temple with multi storied pitch roof. This roof consists of double-hung windows, with upper sashes and louvers often broken up into smaller panes. During extension of built area, they often connect the roof system through porches (Figure 6). Generally, the roof angle remains within 30 to 35 degrees conducive to protect from natural storm and heavy rainfall. In order to make offset porch they use both palm leaves and tin (corrugated sheet).

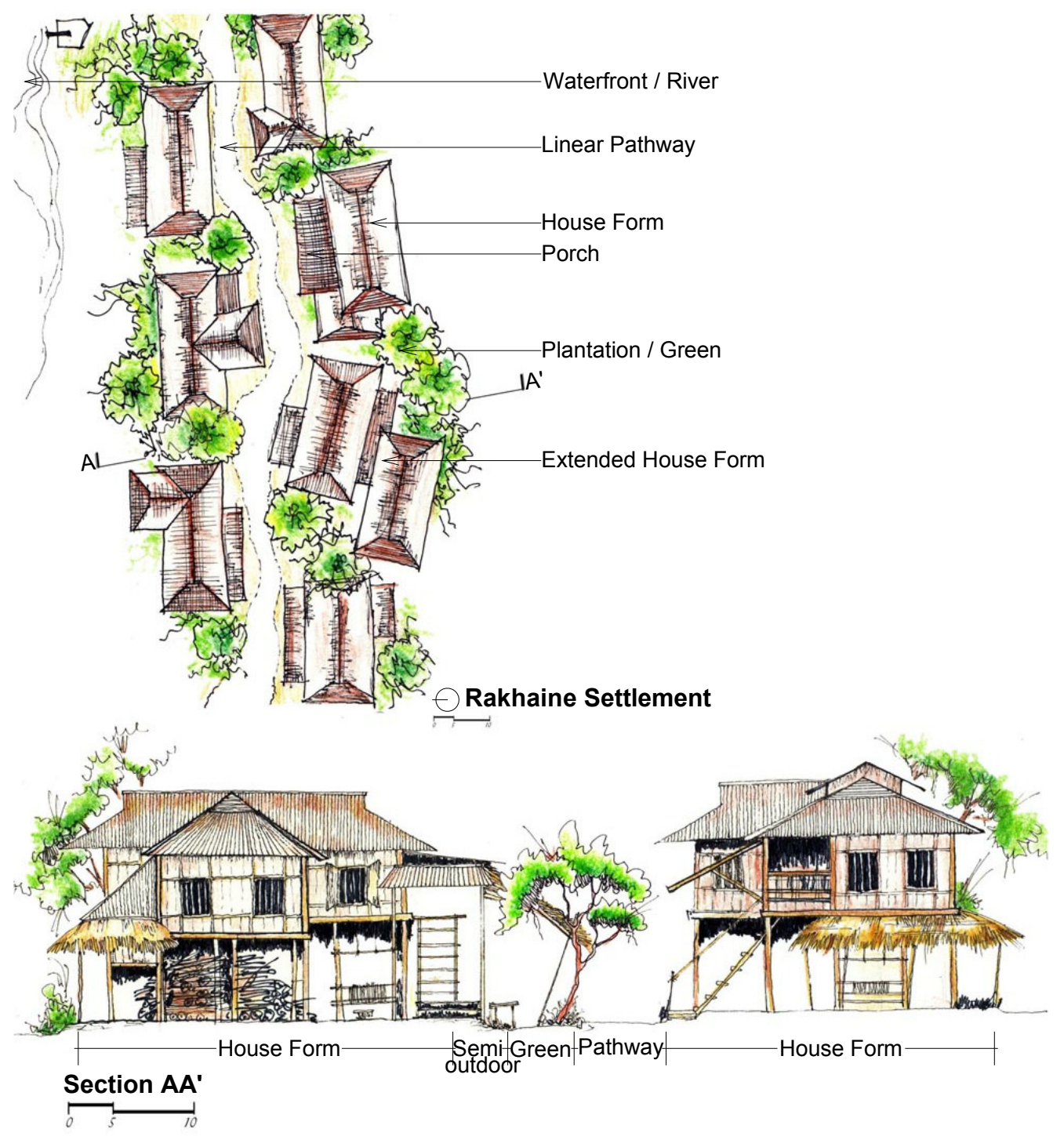

Figure 4. Settlement pattern of a Rakhaine Para 


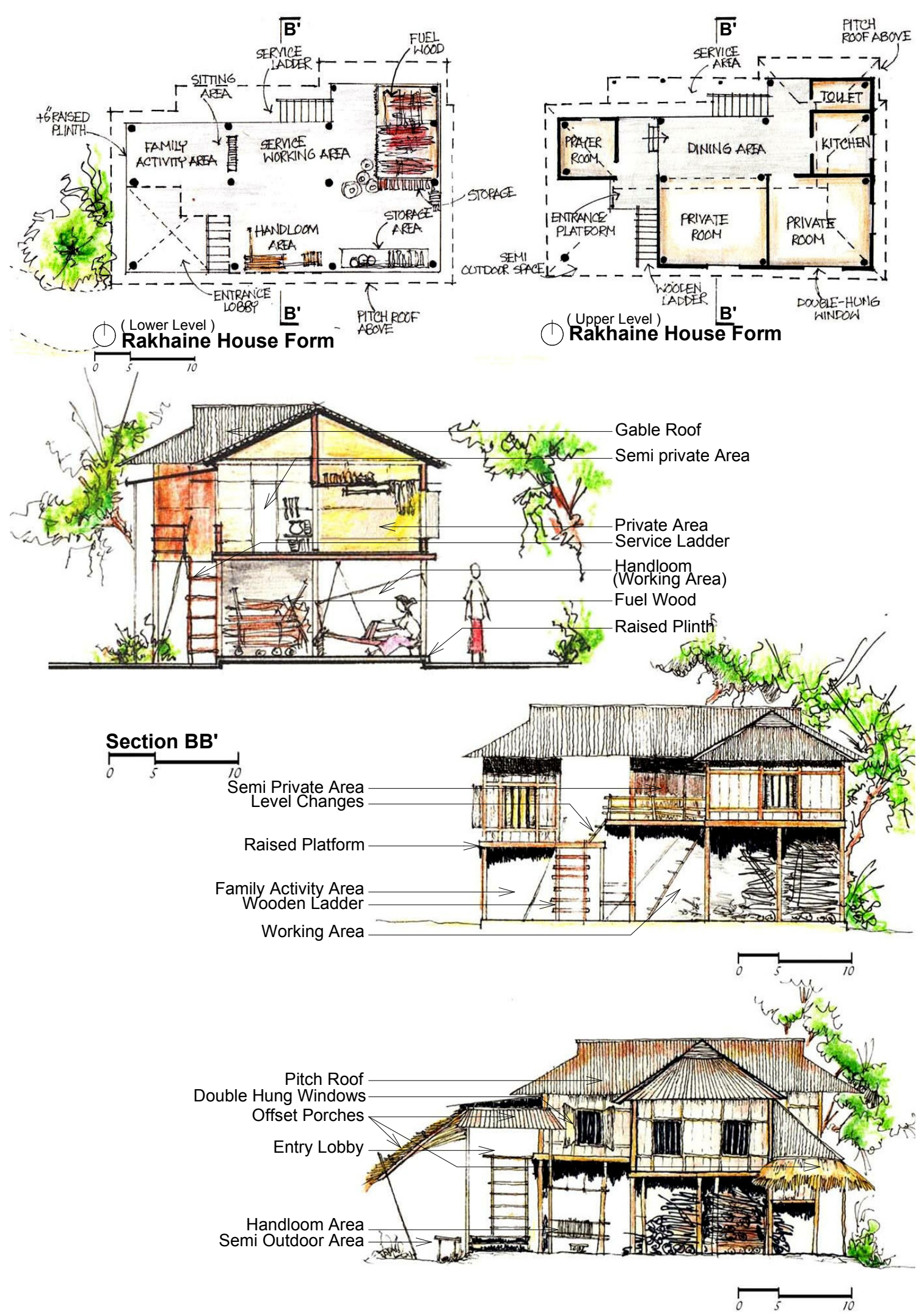

Figure 5. Spatial sequence and uses pattern of Rakhaine houses and some details of a section and elevations Source: Author - 2017 

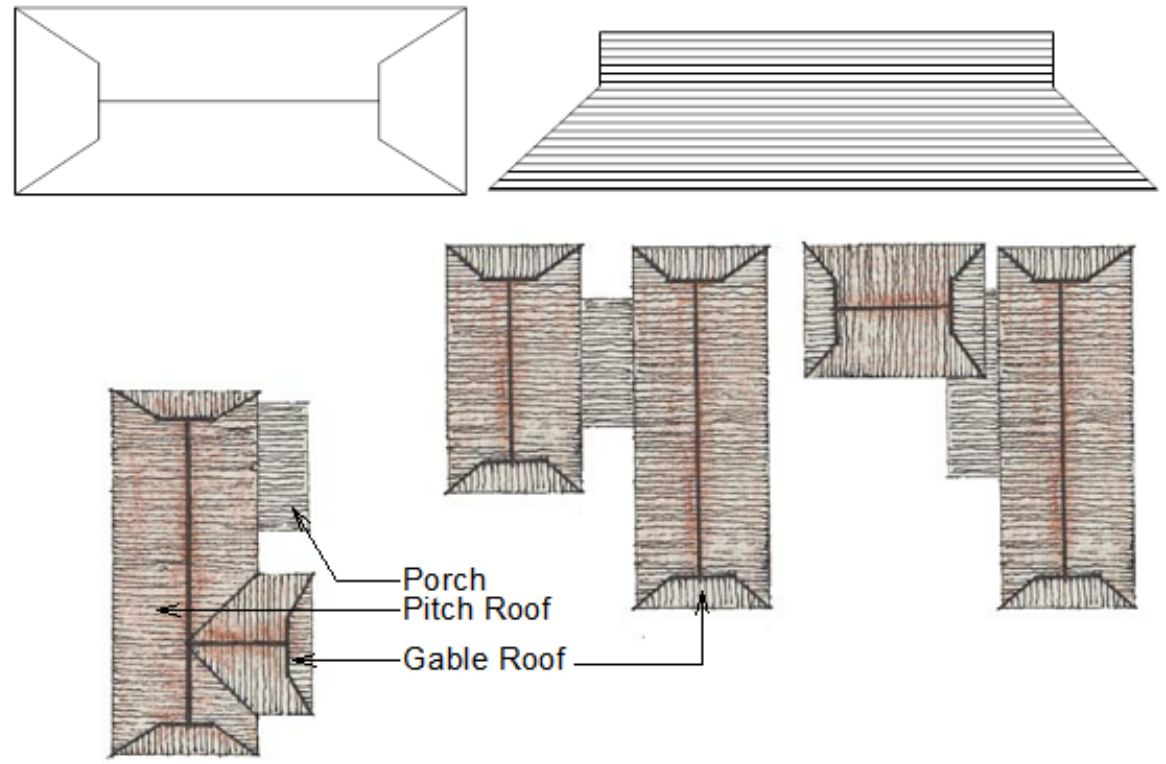

Figure 6. Traditional roof pattern, orientation and form formulation of Rakhaine houses

Source: Author 2017.

\subsection{Archetype of Rakhine's Settlement}

Usually, Rakhines settlement follows a spin like linear corridor which passes through the middle of the area. It also has some number of branches of corridors that connected with the main spine corridor. Proportionate pocket like space at the beginning of every family unit connected with spine as well. The settlement has also systematized with a lot of vegetation and plantation around every family unit that makes the area private (Photograph 1). However, individual service facilities some time share with the adjacent family unit within the area.
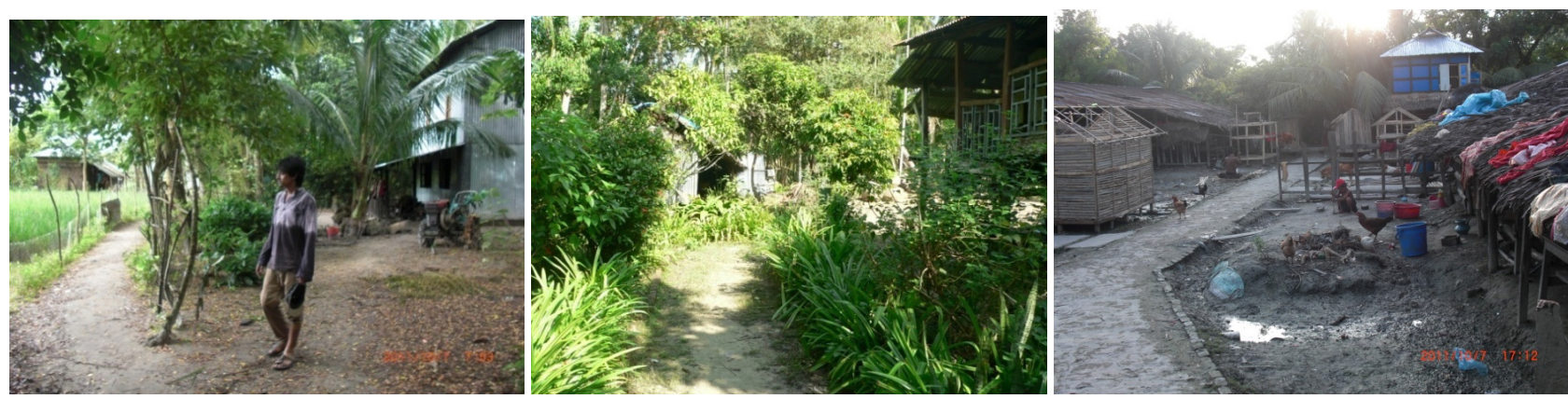

Photograph 1. Linier corridor, vegetation and Spine pass through settlement
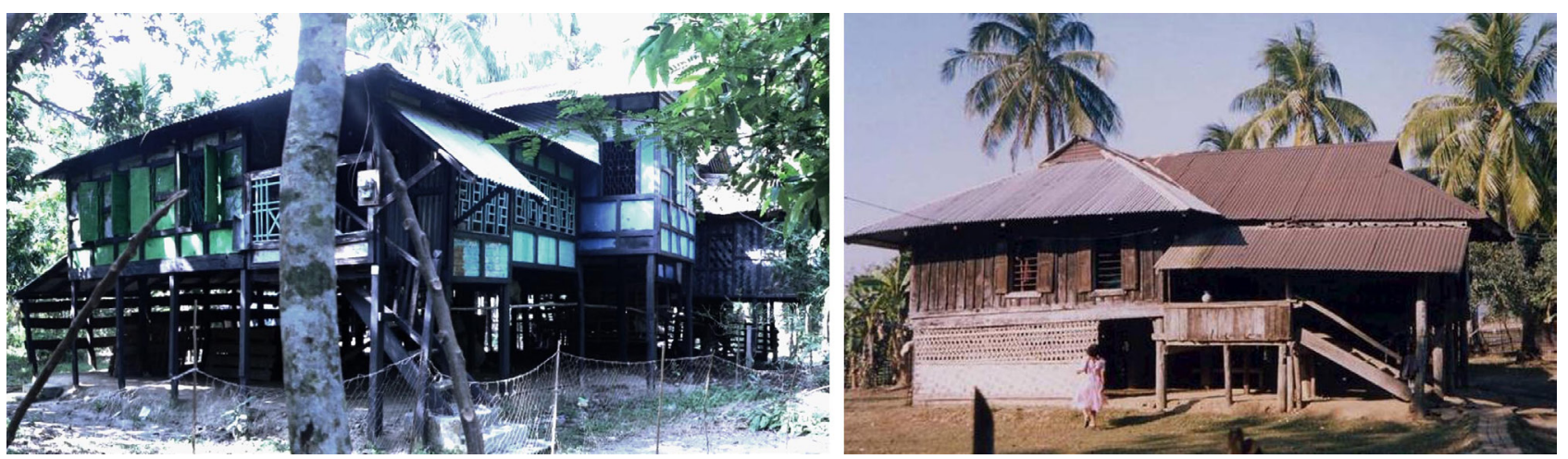

Photograph 2. Rakhaine house form with different orientation of gable roof 

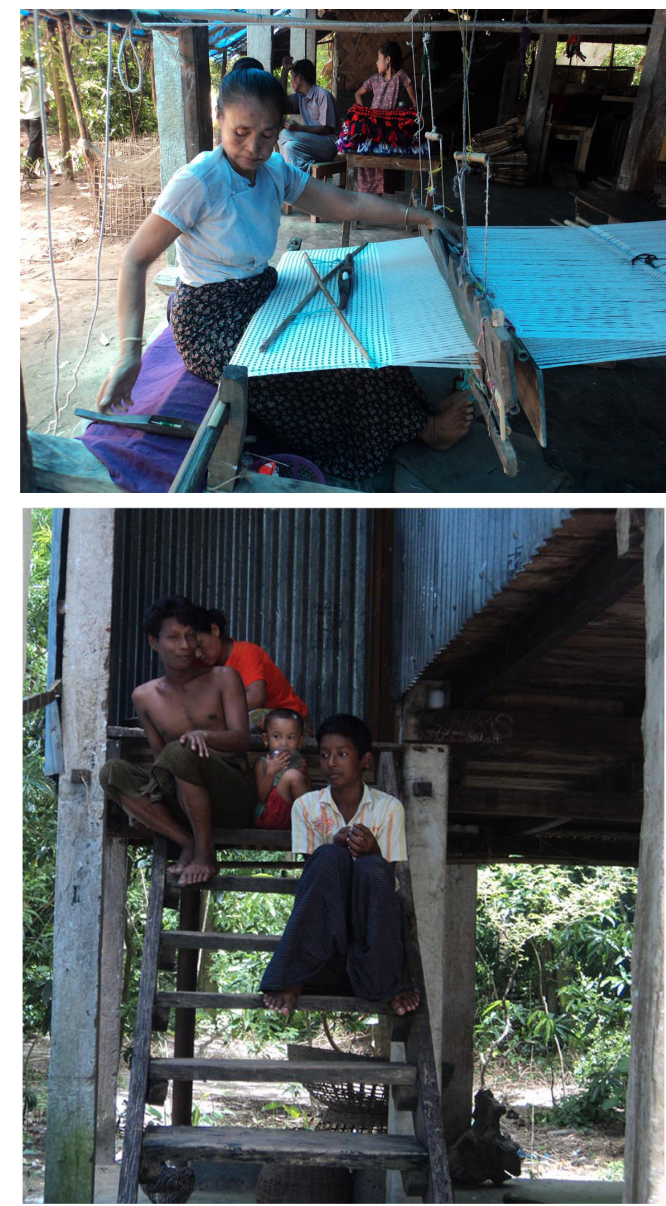

Photograph 3. Weaving area and family activity area

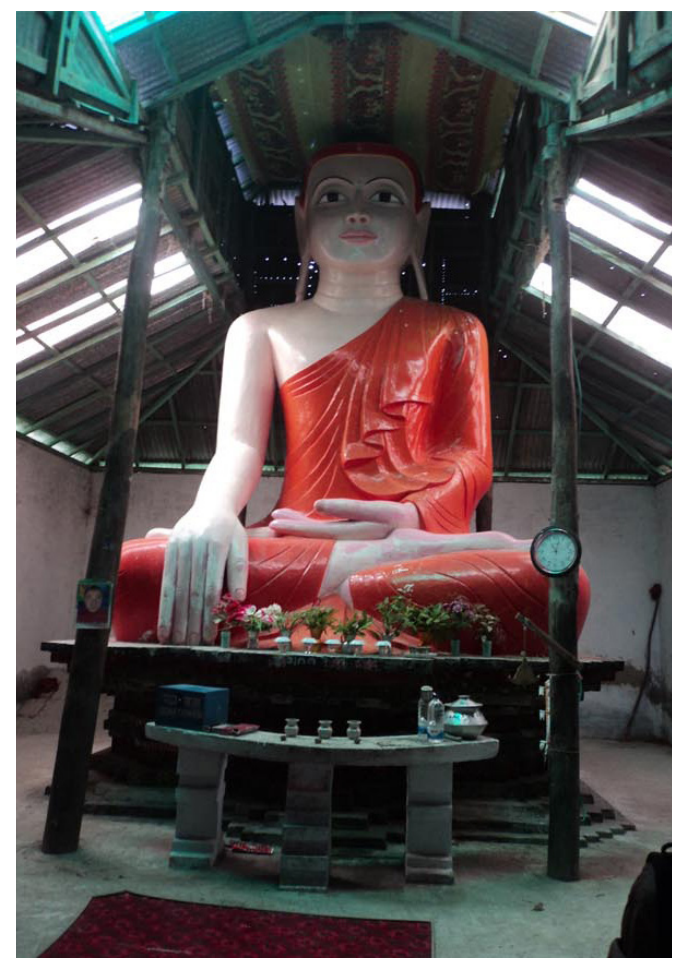

Photograph 4. Khiongs or Bihara (Rakhaine Temple)

\subsection{Opening}

The openings are remarkably different from Bengali rural houses. Lightweight sliding doors made from bamboo matting can be noted as the main door type in most settlements under this study. The window is limited to a large number and set adjacent to ground floor. Ornamented wooden frame is used around veranda and sometimes it differentiates the functions and activity areas. Generally, the style of windows is double hung with upper sashes and the use of louvers often broken up into smaller panels.

\subsection{Housing Materials and Construction Tech- nique}

Similar to Arakan the vegetation and natural landscape of Potuakhlai and Cox's bazar are favorable to grow timber, such as segun (teak), chamble and gurjan. Since these kinds of timbers are more popular as building materials of this indigenous community. Usually, the Rakhaine houses are built on stilts and this stilts basically a post and lintel structure with the timber walls and a thatched roof. Floors and walls are made of timber as well. The exterior walls are non-load-bearing, prefabricated elements with light weight bamboo and timber. Almost all parts of the house exhibit the use of timber in different ways which are shown in Figure 7. They use wooden railing in the semi outdoor spaces with different kind of ornamentation and details. The details and ornamentations of the cornice are highly appreciable. Corrugated steel sheet (tin) is used as roof materials. Secondary roof is arranged beneath the main roof to reduce the heat and expresses the activity area.

\subsection{Temple Structure}

Usually Rakhaine's temple complex comprises of both religious and cultural facilities. It is often using as a community school for their children. The main shrine of the khiongs (Bihara; Rakhaine Temple) shown in Photograph 4 is entered through a semi outdoor pavilion space which is often used as schooling facilities or shorter prayer. The main shrine splits into three, chamber for the sculpture of Lord Buddha, main prayer space and priest rest space (Figure 8). Sometime service like kitchen is added with the main shrine. Temple is the largest built form of their settlement with multiple roofing. The roof height has gradually increased in order to hold the large statue of Buddha. 


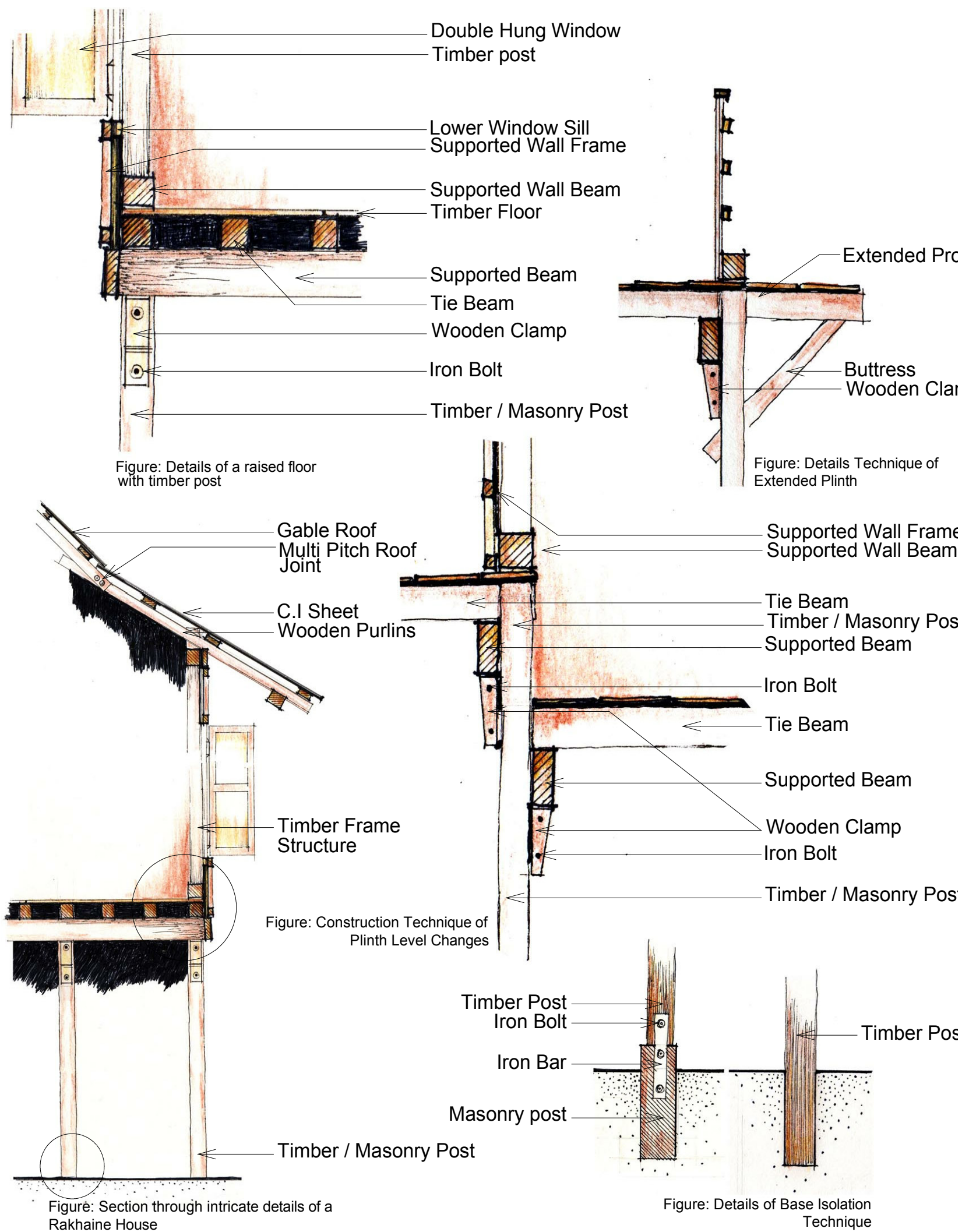

Figure 7. Sophisticated construction details and techniques of traditional Rakhaine houses

Source: Author 2017. 


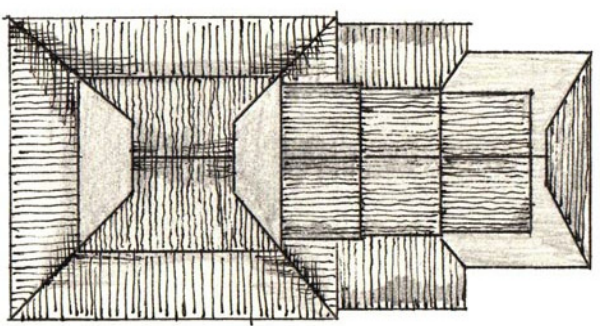

\section{Rakhaine Temple}

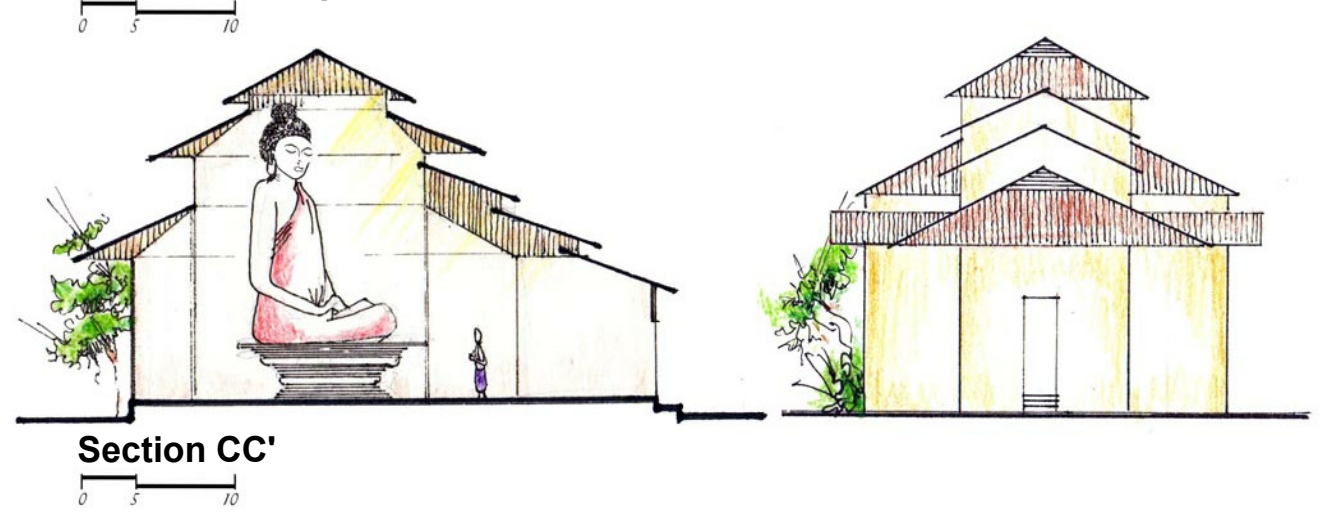

Figure 8. A typical Rakhaine Temple

Source: Author - 2017

\section{Conclusions}

Indigenous people around the world have their own distinctive culture and housing pattern that keeps them safe from all types of natural and environmental hazards in addition to making a sustainable arrangement with a wealthy lifestyle ${ }^{[16,17]}$. This distinctive lifestyle also offers them to contribute various contemporary methods with local available materials and practices which are significant in the field of sustainable architecture. Likewise indigenous community like Rakhaine built form in Bangladesh has certain simplicity with respect to nature within their settlement pattern and construction technique. Therefore, this study was carried out in order to identify settlement pattern and house form of indigenous Rakhaine community and disclose their development style and result inside their terrain. This study found that they like to build their settlements adjacent to nature compare to live within cities and growing and making their own household products which are very simple and functional but distinctive. In addition, this study also found that Rakhaine has a very distinctive settlement pattern with a successful community interactive dwelling space which they learn chronologically from the earlier period. Although, due to availability of various contemporary materials, rapid changes of environment, environmental hazards and loss of local materials they could misplace their technique and individuality. Therefore, this study is significant to preserve and protect their rich cultural identity and tradition. Yet examine their built form through ethnographic methodology can be more helpful to know the communication between environment, people and architecture within this particular situation. Finally, we consider that Rakhaine built form and construction technique that explains on sustainability with contextual identity may assist everyone to become skilled at more about indigenous people's house pattern and built form technique and their existence in prospect.

\section{References}

[1] Barman C. and Chakma P. (2010), Human Rights Report 2009-2010 on Indigenous Peoples in Bangladesh, Kapaeeng Foundation.

[2] Roza, F. (2020),'Indigenous People of Bangladesh: Barrier and How to Overcome the Barriers", Department of Management Studies, Faculty of Business Studies, Bangladesh University of Professionals.

[3] Smith M., (2019), Arakan (Rakhine State) A Land in Conflict on Myanmar's Western Frontier, Transnational Institute (tni), De Wittenstraat 25, 1052 AK Amsterdam, The Netherlands.

[4] Mustafa M. (2005), The Rakhaines: Aborigines in Bangladesh. Dhaka: Mowla Brothers.

[5] Cho, V. (2017), Ethnicity and Identity, Routledge Handbook of Contemporary Myanmar, 1st Edition, eBook ISBN9781315743677, Pages - 9 . 
[6] Khaing, T. S. (1995), The Rakhaing Tanzaung Magazine, No, 18.

[7] Aung C. T. (2008), The problem facing past culture of Rakhain tribal; Published by Maung Mang Nine (Maung Mang), 1st edition.

[8] Tun O. S. (2005), Thongran and Rakhine culture, The Rakhaing Review 4, Pp: 63-64.

[9] Ashadul I. (2013), Changing Rakhaine Adivasi Culture of Bangladesh: A study Of the Birth, Death and Marriage ritual.

[10] Hall E. D. G. (1964), A History of South-East Asia, Published: Macmillan; St. Martin's P.

[11] Mohsin A. (2000), A State of Minority Rights in Bangladesh, Journal for International Center for Ethnic Studies, Colombo, Vol. 4, No. 3\&4.

[12] Aung M. B. (2008), Nga Ro Rakhaing; Publish by Maung Mang Nine (Maung Mang); $1^{\text {st }}$ edition, Pp: 107.

[13] Mohajan and Haradhan, (2018), History of Rakhine State and the Origin of the Rohingya Muslims,
Premier University, Chittagong, Bangladesh, MPRA Paper No. 88186, posted 28 Jul 2018 13:24 UTC.

[14] Baird R. (2008), The Impact of Climate Change on Minorities and Indigenous Peoples, Minority Rights Group International, 54 Commercial Street, London E1 6LT, United Kingdom, ISBN 978-1-904584-75-9.

[15] Khaing T. S. (1994), Rakhaine Mahamuni Phara Tha-hmaing (in Rakhaine), ed.1, 3d-1991, Rangoon, Burma, Pp:14; Quoted: Maung Than Aye, 'Identities of the Rakhaing Community', The Rakhaing, Vol.1.

[16] Islam S., Rahman M., Hasan T.M., Mowla Q.A. (2016), A Study on the Settlement Morphology of Indigenous Khasi Community in Sylhet, Bangladesh, PRATNATATTVA; Journal of The Department of Archaeology, Jahangir Nagar University, Vol. 21. No.1.

[17] Chowdhury S., Saha K. (2012), Indigenous Housing and Settlement Pattern of Patro (Laleng) Community in Sylhet, International Journal of Engineering and Innovative Technology (IJEIT), Volume 2, Issue 6, Pp: 202-206. 